\title{
Environmental Discourse in Moroccan Eco-documentary: The Decryption of
}

\section{Scientists' Narratives}

\author{
Dr. Mohamed MLILESS \\ m.mliless@edu.umi.ac.ma \\ Dr. Lamiae Azzouzi \\ Associate Professor, Moulay Ismail University, Morocco \\ azzouzilamiae@gmail.com
}

DOI: https://doi.org/10.36892/ijlls.v2i1.201

\section{Received: $10 / 02 / 2020$}

Accepted:

$20 / 3 / 2020$

Keywords:

Eco-Documentary, Ecolinguistics, Experts Discourse, Fear And Threat Expressions

\section{Abstract}

Eco-documentary is a media genre that aims to raise environmental awareness among the general public. It exposes environmental degradations and presents alternatives for environmental issues such as pollution, global warming, and deforestation among others. For this aim, the language of scientific experts contributes a lot to the making of the argumentative flow of the documentary. Within the framework of ecolinguistics, this article examines fear and threat expressions used by scientists to reinforce argumentation in Faouzi's (2012) entitled انين المرجة الزرقاء: whining of the Blue Lagoon/. In this direction, Witte, Cameron, McKeon, \& Berkowitz's (1996) model of "perceived severity" and "perceived susceptibility" was adopted to explain the use of fear and threat appeals in the film. The results show that 'perceived severity' and 'perceived susceptibility' expressions are preponderant in experts' discourse. This study has many implications for eco-documentary producers, governmental and non-governmental organs, and future research in Morocco to explore other facets of films that report about man's damages perpetrated to environmental settings and resources.

\section{INTRODUCTION}

Documentaries bring the audience into new issues and experiences through the presentation of real information about people, places, and events; generally portrayed through the use of factual images and discourse (Mliless, 2020). For Bernard, (2007), a documentary is what a filmmaker does with "factual elements, weaving them into an overall narrative that strives to be as compelling as it is truthful and is often greater than the sum of its parts" (p. 2 ). In eco-documentaries, the central theme is always the natural element and related degradations. The eco-documentary, a founding genre of the cinema (Aitken, 2013), is a platform within which many discourses report about environmental crises (Hughes, 2014). Moreover, it illustrates environmental realities that are arranged according to a logical process so as to document the degradation of natural components (Nichols, 1991; 2001). Ecodocumentary making requires deep engagements from the maker to "limit as well as justify the role of film-making in environmental degradation through what films offer to the global dissemination of environmental consciousness" (Hughes, 2014, p. 5). In the aftermath of the United Nations Conference on 'Environment and Development' held in Rio de Janeiro and the 'Kyoto Protocol', eco-documentaries started to focus on the role of the Anthropocene; to show the impact of humans on the ecosystem (Arthus-Bertrand, 2009; Hulot \& Lièvre, 2009; Laurie, Bender \& Burns, 2006; Milne, 2008; Terry, 2010). To improve this genre, many film festivals are permanently organized worldwide (Cinemambiente, Turin; International 
Environmental Film Festival, Barcelona; Eco Film Festival, Patagonia; Nature/Voices of Nature Environmental Film Festival, Florida; Environmental Film Festival, Tunis; Nile Environmental Film Festival, Egypt; Ait-Ourir International Film Festival, Agadir; and Environment Films, Chefchaouen).

Devoid of its theme, a documentary mixes many narratives to inform and persuade viewers; above all, to reflect "situation, condition, and culture of a society" (Chamalah, Nuryatin, Sayuti \& Zulaeha, 2019, p. 60). The filmmaker calls upon actors to present their stories and testimonies on environmental realities the making of which does not allow for the reconstruction of past events. The eco-documentary understudy "anin almarja zarqa" reports about a natural degradation of a lagoon in the northeast of Morocco. The theme is commented by many actors including a voice-over, laymen, and two scientific scholars. This research aims to decrypt the language of two scientists when they articulate their scientific knowledge on the issue. Their testimonies are to back up the argumentative flow, to achieve public immersion, to serve the plot, and to perpetuate the remembrance of the film. For this aim, two scientists' narratives (Mohammed Dakki and Abdeljabbar Kaninia, members of a research group in the Rabat Scientific Institute) strengthen the plausibility of the environmental problem. Hitting viewers' rational logic is a strategy that drives the audience to believe and embrace the story of the eco-documentary. The scientific doses injected in the documentary give assurance and make the audience appreciate science. In fact, their contributions can perpetuate the film's remembrance. Proof that science mixed with documentation can deeply affect people is that many individuals across the globe remember 'The Core', a disaster film in which the characters go on a mission to the terrestrial core. Similarly, 'Home' remains firmly rooted in people's minds, so much so that the eco-documentary has become a benchmark for the invaluable earth that we should preserve if we are to avoid a new wave of mass extinction. Though eco-documentaries have the vocation to attract crowds, provoke reflection, and engrave events in people's minds, scientists' discourse is discarded as much interest is devoted to visuals.

\subsection{Problem of the Study}

For years, documentaries have treated the environment as an issue that concerns human existence. To plead for a safer and a sustained world, eco-documentaries have become a means to deny man's abuses on nature. It should be mentioned that eco-documentary production in Morocco is very limited and research on its language is rare. As an exception, Saidi (2018) and Mliless (2020) have dealt with Amouddou's eco-documentaries (a Moroccan production agency) from different perspectives. In fact, Saidi's (2018) study did not account for the way discourse was constructed to raise environmental awareness; it is more informative in that it provides theoretical information on the way thoughts and images are linked. The study focused on the difference between scientific documentary and fiction documentary, as well as it exposes the role of memory, culture, and literature in Amouddou's documentaries. Saidi's (2018) study was general and theoretical; her work paves the way for other researchers to explore the challenges and perspectives of the documentary films in Morocco. Nevertheless, Mliless (2020) on environmental discourse in Amouddou eco-documentary investigated the linguistic features used in all characters' narratives including a voice-over narrator, the ordinary witnesses, and the experts whose discourse has contributed a lot to the making of the film. The book investigated patterns of induced fear and threat in all actors' language to reinforce the objectives of the film. Concerning the issue at hand, it is important to highlight that fear and threat expressions when encapsulated in discourse they might have a profound impact on the audience.

\subsection{Importance and the Rational for the Study}


To report about environmental precautions, fear and threat structures are widely used in contemporary eco-documentaries. Most of the time, the degradation, not to say extinction, of many environmental components, is attributed to the Anthropocene; the impact of uncontrolled human behaviors on nature. The importance of environmental discourse, which is influenced by situations and disasters, pushes us to examine the implication of fear and threat expressions on the argumentative flow of the film. Intrinsically, this work has been influenced by previous works on discourse analysis, particularly that of the environment (Mliless \& Larouz, 2018; Mliless, Larouz, \& Yachoulti, 2019; Mliless, 2020). Considered as a challenging topic in media and discourse studies, this work treats experts' discourse from an ecolinguistic and discourse analysis perspective. While critical discourse analysis has contributed so much to this field (Altman, 1999; Bednarek, 2010; Branigan, 1992; Iedema, 2003 Kozloff, 1988, 2000; McIntyre \& Culpeper, 2010; Piazza, 2006, 2010, 2011; Quaglio, 2008, 2009; Short, 2007; Stokoe, 2008), research has undermined this issue in the Moroccan context; we do not know much about the role of fear appeals in experts' narratives that could be impactful when mixed to the scientific knowledge.

\section{REVIEW OF THE LITERATURE}

The term eco-documentary is often difficult to delimit and any attempt to do so needs to take into account the historical context to trace how and when it started. A documentary is not a fiction movie; it is a serious movie that teaches people through recorded human, social, physical, and environmental realities (Aitken, 2013; Aufderheide, 2007). So, what types of documentaries are there?

\subsection{Aufderheide's Typology}

To account for this typology, Aufderheide (2007) lists a myriad of subgenres that she thinks fall under the term of documentary: public affairs, government propaganda, advocacy, history, ethnography, and environment. Generally, these genres are about a) information that can go far beyond the limits of news reports, b) fallacious production that serves governments and organization which produce it, c) past events despite data shortage when it comes to the documentation of remote and ancient happenings, d) humans and their behaviors induced by geographical, climatic, political, social, or natural conditions, and e) pollution, global warming, exploitation and depletion of natural resources among others. At a time when the world is under shocking realities of natural disasters, the debates to preserve the environment are starting to gain ground. In the Moroccan context, eco-documentaries are marked by prominent productions of Amouddou producing agency. We assume that Amouddou eco-films are blossoming roses in an arid media landscape that is governed by industrial productions of fiction and soap opera. Amouddou's eco-documentaries show high techniques that allow easy making and treatment of environmental topics.

\subsection{Fiction and (Eco) documentary}

The distinction between documentary and fiction films is always made on the levels of reality and imagination. Though fiction and non-fiction films can be seen as two domains that inhabit one another (Renov, 1993), the difference between the two is made on the extent to which reality and imagination are reported. Reporting about environmental issues is a challenge that documentaries try to surmount. Often, documentaries draw on fictional techniques to foster believes about the world. According to Sufi (2014), the purpose of ecodocumentaries is to educate and disseminate environmentally conscious messages. For Ellis (2000), eco-documentaries share fictional properties of the image and the way it is represented; in fact, both types share "concerns about screen language, narrativity, and issues of performance" (Chapman, 2009, p.15). Despite recognized inconsistencies, there are some shared technical features namely creative elements, music arrangements, 
expositional editing and crosscutting, close-ups for dramatic effect, as well as character development (Chapman, 2009).

\section{Table 1. Differences between Documentary and Fiction Films}

\begin{tabular}{|c|c|c|}
\hline & Documentary & Fiction \\
\hline Humans & - Ordinary/expert people. & - Characters. \\
\hline Exhibition & $\begin{array}{l}\text { - Implementation/ } \\
\text { reconstitution. }\end{array}$ & - $\quad$ Staging. \\
\hline Purpose & - Inform, explain, present. & - $\quad$ Entertain, amuse, amaze. \\
\hline Places & - Natural - real - even recreated. & $\begin{array}{l}\text { - Imagined or reconstructed } \\
\text { decorations. }\end{array}$ \\
\hline Subject & - $\quad$ Past reality, present, future. & - Imagined or adapted history \\
\hline
\end{tabular}

Whatever eco-documentaries convey in terms of testimonies and interpretations of environmental disasters, they will always rely on fiction techniques to document the realities of the ecosystem. Whether told by experts or ordinary people, the documentary includes narratives and testimonies of the environmental reality. Among the discourses, the scientific language is utilized in the documentary under study to provide a scientific justification for the degradation of the lagoon.

\subsection{Environmental Discourse}

Simply put, discourse refers to a shared way through which people understand the world around them. In the environmental context, this form of communication is done through the way individuals perceive nature around them, express their ideas, and tell their experiences about environmental problems. The documentary under investigation involves many actors who adopt different discourses to express diverse interests and positions. Convinced of the importance of environmental discourse, Muhlhausler, and Peace (2006) define it as the specific way of "talking about particular environments and their futures.... as comprising the linguistic devices articulating arguments about the relationship between humans and the natural environment" (p. 458). Interestingly, the words 'environment' and 'nature' are central to comprehend the intricacy of this discourse. For Hochman (1997), the term 'environment' has increasingly come to mean "a nature tangibly important only to human health and livelihood" (p. 82). Nevertheless, the term has been criticized for being too vague (Howard, 1978; Rowe, 1989; Fill, 1993; Williams, 1983), perhaps the most complex word in the language; a culturally constructed concept that can produce "inconsistency and ambiguity in the terminology used for these assessments" (Taylor, 1990, p. 411).

\subsection{Types of Environmental Discourses}

Environmental discourses, which begun during the industrial revolution, has reflected the impact of man's exploitation of natural resources to obtain growth. For instance, it may reflect scientific, moral, economic, and aesthetic macro discourses (Harre, Brockmeier, and Muhlhausler, 1999), green economic policies (Gerbig, 2000), green consumerism (Elkington, Knight \& Hailes, 1988), green advertising (Muhlhausler, 1996, Luke, 1997; Mliless, Larouz \& Yachoulti, 2019), eco-centric, and anthropocentric discourse (Herndl \& Brown, 1996), and textbook discourse (Mliless \& Larouz, 2018). Similarly, Dryzek (2013) provides a typology that includes four categories: limits and survivalism, promethean and survivalism, sustainability, environmental problem solving, and green radicalism. Overall, 
these types advance that a) unrestrained economic and population growth is eventually too much for the earth to handle, b) uncontrolled economic growth brings about damage to the earth because of the overuse of resources above the carrying capacity, c) strong rejection of compromise and structure of an industrialized society, d) overexploited earth resources and the impacts of human collusion are often denied or regarded as a natural occurrence, and e) achievement of economic prosperity and growth are essential because accumulation of wealth leads to more innovation. Based on the features that environmental discourse embodies, Dryzek (2013) opines that it contains a) the prosaic which takes problems and issues as facts that are troubling the economy and have to be solved, b) the imaginative which redefines environmental issues as problems that can be viewed as opportunities, c) the reformist discourse which aims to make smaller changes to environmental problems, and d) the radical type which aims to make big changes to environmental problems.

\subsection{Experts' Narratives}

By eco-documentaries actors we mean the people who appear speaking in front of the camera (ordinary witnesses and scientific experts) or those who are off (the voice-over narrators). Before dealing with the occurrence and frequency of perceived severity patterns (PSV) and perceived susceptibility patterns (PSP) in experts' narratives, we evoke some general information on the language(s) used by the experts, the time they took to speak, and the frequency of their appearance. Both experts use French to communicate their scientific experiments they have conducted on the lagoon and its species. They appeared in six scenes for ten minutes and four seconds, $20 \%$ of the film's total time. Their appearance was intelligently chosen by the director who introduced them whenever he felt that laymen's common-sense narratives need a logical argument. Though experts' testimonies are in French, the audience can easily understand them through the voice-over actor who assures translation. In the documentary, the experts bear an authoritative role in restoring the past events. Their discourse contains important scientific data they report from studies they conducted on the lagoon as a result of longitudinal tracking of birds for decades. In this sense, experts' narratives bring into the front the man's devastating behaviors exerted on the natural setting. The segmentation of experts' narratives indicates that their rhetoric is rife with PSV and PSP patterns that overshadow the population's responsibility towards the deterioration of the lagoon.

\subsection{Eco-composition and Ecocriticism}

Writing about environmental problems involves skills to mark the relationships between language and actors; it instills environmental awareness and stresses the impact of the Anthropocene on nature. It is mentioned in Dobrin, and Weisser (2002) that environmental settings and discourse rely on disciplines that merge composition, literary studies, communication, cultural studies, linguistics, and philosophy among other hard sciences that study nature namely ecology, and natural science. Writing about damaged environmental locations becomes a difficult activity when it is about thinking, writing, and documenting nature or reporting about nature's destruction. De facto, eco-composition is both a responsibility and a commitment that engages accurate choices of language to value environmental problems and to address dangerous and harmful damages that humans do to the environment (Witte, et al., 1996). It should be made clear that eco-composition must not be mixed with eco-criticism, a field of interest that examines human's attitudes towards the environment as entrenched in writings and literary works about nature. Eco-criticism which analyses environment in literature, (Hodosy, 2018), has been revived by Glotfelty, and Fromm (1996) who define it as "the study of the relationship between literature and environment" (p. xix). Moreover, Dixon (1999) posits that eco-criticism, which is rooted in nature writing as texts for interpretation, examines literary discourses that portray the 
physical or the external world, how moral questions about human interaction with nature are evaluated. In line with eco-criticism pedagogy (Dobrin \& Weisser, 2002), Giddens (2012) proposed that students have to be initiated to eco-composition to improve writing and speaking about ecological issues. For this aim, Giddens' vision is to enhance students to a) read environmental fictions and interpret them as cultural artifacts situated in a specific context, b) examine key metaphors/topoi of environmental writing, and c) consider the authors' purposes, rhetorical strategies, research, and writing processes so that students can draw ideas and approaches from them as they conceptualize, plan, research and compose writing of their own.

The construction of an eco-documentary involves not only language but visuals also. Be it for pollution, global warming, or natural resources exploitation, a documentary comprises visuals for which the choice of an accompanying discourse is required (Mliless, 2020). The narratives and testimonies of actors are what make the discourse of the documentary. Not only the language reports about the environmental preoccupation but it also reflects the interest of the filmmaker to document environmental realities.

\subsection{Fear Appeals in Eco-documentary}

This work aims to focus on the analysis of fear patterns in experts' narratives, an opportunity to investigate the patterns of fear linked to visuals and cinema techniques in a Moroccan environmental film. While visual expressions are shot with greater precision, the linguistic expressions may also carry a considerable force of persuasion. The mixture of the two components requires a sophisticated method to identify and interpret fear and threat structures the deconstruction of which needs a multifaceted approach.

In this direction we should mention Sufi (2014), a study on the implications of fear expressions, who argues that fear constructs can trigger "relatively immediate and/or longterm attitudinal behavioral change" (p.8). He specifies that the impact of the script is firmly attached to the use of fear patterns through which the film seeks to shake the audience's responses. Similarly, Walton (2007) posits that argumentation through fear appeals is "recognized within the social sciences as a type of argument format used [...] to mold public opinion and attitudes through the mass media" (p.131). For example, fear is detected in the discourse of cancer, an enemy (cancer) that poses immediate threats (Cap, 2017). The analysis of fear structures in experts' stories will allow interpreting the horrifying testimonies that constantly oscillate between experts' repeated feelings of preoccupation about the tragic environmental crisis and their alarming calls to relief the lagoon from an imminent disaster. In fact, the balance between scientific information and fear expressions in documentaries is recognized as a "reasonable argument carrying some weight in shifting a burden of proof in a balance of considerations" (Walton, 2007, p. 127).

\subsubsection{Extended Parallel Processing Model}

Since the second half of the twentieth century, scholars have theoretically and practically explained the processing and consequences of fear patterns in language. The extended parallel process (EPPM) of Witte (1992) is one of the practices which explore fear expressions in discourse to clarify how fear constructs can achieve persuasive aims. According to Witte et al. (1996), the constituents of the EPPM are summarized in four elements namely fear, threat, efficacy, danger control, and fear control. Regarding the element of fear, Witte et al. (1996) define it as "an internal reaction comprising psychological and physiological dimensions that may be aroused when a serious and personally relevant threat is perceived" (p.320). In the same direction, the threat is presented by Witte $e t$ al as a danger or harm that exists in the environment whether we experience it or not. Meanwhile, threats could be cognitions or thoughts about the dangers or harms which comprise two dimensions: severity and susceptibility. As for efficacy, Witte et al. (1996) 
provide a definition in which they stipulate that efficacy pertains to "the effectiveness, feasibility, and case with which a recommended response impedes or averts a threat" (p. 320). To simplify this relationship, Health Communication Capacity Collaborative [HCCC], (n. d) indicates that EPPM can be used to identify four distinct audience segments with different combinations of efficacy and threat beliefs. The report shows that each segment responds differently to a particular health issue and, so, would need to be addressed with different health message strategies that increase threat perceptions or increase efficacy beliefs. More illustrations are included in table 2 below.

Table 2. EPPM strategies adopted from HCCC, (n.d)

\section{Belief in effectiveness of solutions and confidence to practice them}

High Threat: Belief that the threat is harmful and that one is at-risk

Danger Control: People take protective action to avoid or reduce the threat. Strategy: Provide calls to action
Doubts about effectiveness of solutions and about one's ability to practice them

Fear Control: People are too afraid to act, just try to reduce their fear and feel better. Strategy: Educate about solutions
Low Threat: Belief Lesser Amount of Danger Control:

that the threat is trivial and that one is not at-risk
People know what to do but are not really motivated to do much.
No Response: People don't feel at risk and don't know what to do about it anyway.

Strategy: Educate about risk and solutions

In compliance with Witte's model, Sufi (2014) decoded factors of fear appeals in three documentaries namely The $11^{\text {th }}$ Hour by Conners, and Conners (2007), The Age of Stupidity by Armstrong (2010), and The Cave by Fisher (2009). He concludes that the intent behind fear patterns is to shock viewers, to encourage greater environmental awareness, to convince the public to relinquish their attitudes and to inspire or encourage change.

\subsection{Approaches to Eco-documentaries Fiction}

The study of environmental discourse in documentaries is a complicated area of research in which more interest needs to be devoted to the production, reception, and the context of the text (Fairclough, 1995). Studies of eco-documentaries have centered on linguistic categories (Bawarshi \& Reiff, 2010; Freedman \& Artemeva, 2008; Sufi, 2014) and human activities towards the environment (Freedman \& Medway, 1994; Paré \& Smart, 1994). In fact, many approaches have analyzed environmental discourse in ecodocumentaries. These include the sociological approach (LovelL, 1971; Nathansohn \& Zuev, 2013; Pauwels, 2010; Sztompka, 2008; Zuev \& Krase, 2017), the literary approach (Buell, 2005; Buell, Heise \& Thornber, 2011; Ivakhiv, 2008), the narrative approach (Chapman, 2009; Nichols, 1991), the rhetorical approach (Basa, 2009; Feldman, Skoldberg, Brown \& Horner, 2004; Hauser, 2002; Rider, 2014), and the semiotic approach (Aslani, 2014; Kress \& Leeuwen, 2006; Martin \& Rose, 2003;Wildfeuer , 2014).

\section{METHODOLOGY}

This work is an interpretive and qualitative study of fear factors in a Moroccan ecodocumentary. It examines experts' narratives that testify about the deteriorating condition of a lagoon. In line with ecolinguistics, the aim of this study is to identify and interpret 'perceived severity' and 'perceived susceptibility' patterns embedded in experts' discourse. To support this objective, examples from experts' narratives will be inserted whenever 
needed to back up their views on the way man's uncontrolled behaviors have endangered the ecosystem of the lagoon.

\subsection{Theoretical Framework}

The interpretation of fear patterns in experts' discourse is important to understand how and what scientific testimonies are used in the eco-documentary. The deconstruction of experts' discourse depends upon what is explicitly and implicitly represented in the text since the constructions of language may have social and psychosocial purposes (Fairclough, 2003). Accordingly, discourse analysis focuses on the study of language use and describes how lexical and grammatical features are used in texts. Studies have shown that texts have different linguistic characteristics, representing systematic patterns of variation that can be investigated under the rubric of the register (Biber, 2012; Biber, Connor \& Upton, 2007; Schiffrin, Tannen \& Hamilton, 2001; Zheni, 2020). This entails the understanding of various linguistic performances that range from words, sentences, and even long texts. The environmental discourse is highly 'intertextual' and 'interdiscursive' (Danesi, 2015) because it is a part of social discourse that people use daily in various ways and to various degrees to talk about environmental issues. The essentiality of discourse analysis to this topic is to situate experts' language within the social and the cultural context given the fact that texts do not have given meanings, but are assigned meanings (van Dijk, 1991; Wodak, $1988,2015)$. In this case, the adoption of critical discourse analysis (CDA) will help us to demystify the way language exerts power on viewers. Concerning the environmental discourse, this work examines the communicative connections between the scientific language, the natural element, and the expressions of fear in experts' narratives. In this framework, ecolinguistics, a branch of linguistics that investigates interactions between any given language and its environment, will also contribute to explain the language practices, especially, when it comes to the implication of characters' narratives and stories that describe environmental problems (Haugen, 1972; Haugen, 2001). Since Haeckel (1866), the issue of ecology has become an interest among scientists who have examined the interaction between humans and living organisms in the environment. Later on, many studies have been conducted on the role of language in society, particularly when language is connected to ecology (Trim, 1959; Haugen, 1971). Following Haugen's notion of "language ecology", other linguists, (Fill, 1998; Mühlhäusler, 2000a, 2000b, 2002, 2003; Halliday, 2001; Mühlhäusler \& Fill, 2001; Mühlhäusler \& Peace, 2006), have examined the relations between language, ecology, and society. They have established the principles of ecolinguistics as a new branch in linguistics. For instance, Halliday (2001), who claims that the destruction of species, pollution and the like are not just problems for the biologists and physicists but are concerns of the applied linguistic community as well. Ecolinguistics, now, embraces environmental discourse analysis, often known as eco-critical discourse analysis, and the language of ecology and environmentalism (Nash, 2015). They both study interactions between humans and the environment and how humans talk about and adapt linguistically to the natural environment (Nash, 2015). Recent concerns of ecolinguistics are too wide. Today, ecolinguistics studies language in relation to the environment through the perspective of macro linguistics, including pragmatics and cognitive implications. It aims to bring into light the importance of the field as a new perspective from which stories and narratives could be explored in environmental discourses.

\subsection{Data Collection}

This research examines patterns of fear and threat in scientists' narratives in a Moroccan eco-documentary by Faouzi (2012), a film of 52 minutes that is basically narrated in standard Arabic. Given the multiplicity of meanings in their narratives, and the difficulties related to the analysis of verbal and visual data, an adequate analytical framework is needed. 
A verbatim of scientists' verbal discourses was transformed into written texts to restore the chronology of narratives aligned with the visual sequences taking into account that patterns of fear and threat are performative and proactive acts meant to influence. For us, their context of use is decisive to understand participants' discourses based on the idea that fears and threat expressions must be relocated in their contexts of enunciation. Practically, we followed Rose's (2001) steps to retrieve, identify inconsistencies and social contexts, and code fear structures used by the two experts in the film. Once these steps have been accomplished, the data was identified based on perceived severity and perceived susceptibility categories (Witte et al., 1996). The goal here is to link the discourse to the film's aim that seeks to make the viewer more committed to its point of view; we assume that fear can consolidate experts' narratives, whose presence in the film is meant to plead for the preservation of the environmental setting.

\section{RESULTS}

The scan of experts' narratives shows that PSV and PSP patterns are employed to make the audience reconsider man's relationships with the lagoon, a primary source of life that is doomed to extinction. Fear structures are related to threats posed by urbanization, pollution, and the transformation of sweet water to saline. To explain that, this research unfolds frequencies of PSV and PSP patterns on the severity of the situation. In this sense, the results show that fear and threat expressions devoted to the community living by the lagoon show high occurrences of PSVs (6 patterns) on the detriment of PSP structures (2 patterns). Precisely, four PSV and three PSP structures mirror experts' fears about the future of the lagoon. Less frequently, five PSV expressions were used to report their preoccupations about species' saying that human mistreatments of birds and fish are causing much harm to wildlife (see table three below for more illustrations).

\section{Table 3: Experts' PSV and PSP patterns}

\begin{tabular}{|ccccccc|}
\multicolumn{1}{c}{ PSV Patterns } & \multicolumn{5}{c|}{ PSP Patterns } \\
$\begin{array}{c}\text { Community } \\
\text { Species }\end{array}$ & Lagoon & & & Community & Lagoon & Species \\
\hline $\mathbf{6}$ & $\mathbf{4}$ & $\mathbf{5}$ & $\mathbf{0}$ & $\mathbf{2}$ & $\mathbf{3}$ & \\
& & & & & & \\
\hline
\end{tabular}

\subsection{Fear and Threat Patterns about the Community}

It is crystallized in experts' narratives that man's activities and living modes have accentuated the exploitation of the lagoon's resources. As indicated in their field research, the scientists say that the community living by the lagoon is responsible for the ecological doom perpetrated on the setting and species. In this direction, powerful severity arguments occur when the experts explicitly connect between the environmental disaster and illegal hunting that is permanently violating the property. More fear appeals are detected in experts' discourse when they talk about threats related to successive waves of tourists, the use of chemical substances in farming, and the use of the lagoon's water to irrigation large acres of agricultural land. Concerning the adoption of PSP structures, the scientists evoked the magnitude of the environmental problem aggravated by man's uncontrolled interventions; the population's collusion speeds the loss of many natural resources. The encroachment of the lagoon and humans leads to severe mismanagement of natural resources. In this direction, the disrespect of the public space, manifested in modern farming, is explained by 
the population's need to improve social and economic conditions. To satisfy living necessities, the experts let know that the population has been permanently confiscating the lagoon to acquire more land for farming and grazing. To secure farms and agricultural areas, the experts fear that constructed barriers are widening the gap between the natural habitats and different species. Hopefully, the experts show a strong wish to see these threats reduced. They aspire to see man's interventions regulated mainly when it comes to fishing, hunting, and grazing activities.

\section{Table 4: Fear and threat expressions about the community}

\section{PSV Patterns}

\section{PSP Patterns}

1. The environmental crisis is due to the population's uncontrolled activities, illegal hunting, and continuous violation of the lagoon on many levels.

2. Successive waves of tourists come to visit the lagoon are damaging the place.

3. The use of chemical substances for farming affects the place.

4. The use of the lake's water to irrigate farm has severely impacted the water reserve.

5. Our strong wish is to see threats reduced, restricted and regulated when it comes to human activities injuring the lagoon.

6. The place may lose its role as a source of living for humans, birds, and animals.
1. The population has lost a commercial and economic value because of a small error committed by humans

2. Encroachment of human and agricultural activities is related to the misuse of public space.

\subsection{Fear and Threat Patterns about the Lagoon}

The present status of the lagoon and the many threats facing it are reported in the experts' scientific testimonies. They mention that the setting is a dynamic and complex ecosystem in which both humans and species living modes intermingle. In line with their scientific findings, they assert that the lagoon has been significantly influenced by human activities perceived as the most significant threat ever. Explicitly, their fears are directed to groundwater that is turning salt because of irrigation aims, precisely in periods of drought. In the same line, they express fearful concern regarding the use of fertilizers and pesticides. Pollution related to chemical substances when used for farming, say one of the experts, threatens the lives of species and affects air and water quality. A rapid shortage of freshwater could quickly lead to water insufficiency. To illustrate this preoccupation, the experts opine that hydrological modification by which sweet water turns to salt, allows other phenomena to flourish and threaten the lagoon. Additionally, natural dysfunctioning is favored by human uncontrolled behaviors such as domestic and agricultural fertilizers, wastewater, detergents, and industrial releases among others show a permanent threat to the lagoon's existence. For example, the proliferation of saltwater plants and vegetation (sea-grass, marine algae, and other saltwater macrophytes) threatens sweet water resources furnished by the lagoon. What they suggest is that phosphorus release of in water should be controlled otherwise criterion quality related to sensory parameters (smell, taste, and color) will be seriously affected and disrupted by notorious plants. They argue that the superficial zone occupied by seaweed was strictly limited in 1997. Today, these plants are gaining more space in the lagoon and will propagate dramatically across in the coming decades. Regarding the use of PSP expressions, the experts advance that farming, fishing, and hunting activities are contradictory to the universal regulations and laws on the protection of wetlands (RAMSAR convention, 2013). To show more regrets, Experts' scientific preoccupations 
towards the present situation of the lagoon are expressed through a dramatic mode. They judged that what has happened so far to the lagoon is unacceptable given the fact that the place is losing its natural significance as a suitable ecosystem for birds.

\section{Table 5: Fear and threat expressions about the lagoon}

\section{PSV Patterns $\quad$ PSP Patterns}

1. We are afraid that groundwater turns to salt if it is overused for irrigation in drought periods.

2. The water is turning salt, what heralds this aspect is that some salt waters plants which were limited in space in the 1997's, are propagating through the lake.

3. Today saltwater plants are occupying a large area in the lagoon on the behalf of other plants that grow in sweet waters.

4. The average of water has remarkably diminished.

\subsection{Fear and Threat Patterns about Species}

Like any other wetland, the Sidi Boughaba lagoon has been subject to human sabotage that includes the tracking and hunting of birds and the destruction of feeding areas and birthing grounds. To illustrate human threats, the scientists evoke that bird categories are severely perturbed and intersected when it comes to the migration cycle. For the two experts, birds have been their research concern and that of the research group they are affiliated to. On many occasions, they say that the lagoon has been subject to ongoing degradation and loss due to man-induced activities. In this sense, we site a longitudinal study by Dakki, CherKaoui, Lahrouz, and Saâd (2013) who argues that for many decades, the lagoon has been a perfect location for significant migrant populations and colonies of birds to nest and roost (225 species of birds, 227 species of fishes, 35 species of crabs, 19 species of prawn, 14 species of marine algae, 5 species of sea-grass, 2 species of marine mammal among others). To explain the present hazardous and critical situation of species, they use PSV expressions that document birds and fish populations' permanent risk in breeding periods due to human irregular fishing. Accordingly, man's uncontrolled activities have decreased fish quantity in that some fish types no longer exist in the lagoon. Similarly, scientists notify that birds are facing the same fate too. Their fears are elucidated in the alarming results of a survey they effectuated since the 90 s evoking that the loss of habitat due to rampant urban development, illegal hunting, uncontrolled land and fisheries management, and successive periods of drought have brutally affected the number of birds. Regrettably, the construction of many infrastructures near the lagoon will worsen the continuity of the setting for the coming decades. Experts' regrets are rooted in scientific data stressing that bird colonies are flagrantly decreasing. To illustrate that, the experts mention statistics to crystalize that a) the whistling ducks, a category that used to count more 20000, count today 7000 , b) flamingos have decreased to 250 species while this category counted more than 2500 . Dramatically, the experts articulate that man's exploitation of the lagoon is negatively affecting the biodiversity of the lagoon, causes the decrease of species, augmenting their mortality rates, and favors the loss of species' habitat. Based on scientific data, the scientists predict that the number of species will decline and even some categories may disappear if the lagoon remains exposed to man's unfair exploitation. Though experts' discourse provides solutions to block man's threats, the testimonies they afford show explicit engagements of governmental institutions, non-governmental organizations, and the communities residing by the lagoon. Experts' discourse should materialize their 
recommendations by clearly saying that the government and the population must ban and control illegal hunting and fishing, restrict human access to the area by putting the lagoon under permanent watch, and activating drastic penal measures for those who break the laws. The choice of narrative modes matters a lot. It is well thought from the part of the director to determine perspectives and standpoints from which viewers are called to experience the documentary. For instance, experts' mode of narration has established psychological and cognitive relationship between the audience and the theme of the documentary. Many modes of narration were adopted by experts when they scientifically express their fears about human threats and menaces to the lagoon. The experts' narratives are apocalyptic in that they contain expressions implying impending ecological crisis and depicting catastrophic effects of human interventions on the environmental setting. Similarly, their discourse expresses a jeremiad mode through which they assign the responsibility for human behavior to the destruction of the lagoon. In the same sense, experts' narratives have a hopeful flow that depicts positive images which might be eco-friendly solutions to the dramatic deterioration of the lagoon. Not only that, experts' testimonies reflect an environmental nostalgia as images of natural environments are reported in experts' narratives to evoke an emotive response in relation to a prosperous and lively lake that used to be the place for many species namely birds. Linked to the nostalgic memories of the lagoon, the experts' narratives use a sublime mode to develop environmental awareness about a magnificent setting and the living species. Finally, scientists' discourse has been an environmental melodrama and an authoritative scientific platform through which the documentary sensitizes viewers, social actors, and the community living by the lake to show more emotive responses and actions towards the protection of the lagoon.

\section{Table 6. Fear and threat expressions about Species}

\section{PSV Patterns}

PSP Patterns

1. Fishing activities have decreased to the extent that some types of fish do no longer come to this place for production.

2. Illegal fishing during breeding periods.

3. The scarcity of rain has influenced the number of birds.

4. We noticed a regression in some birds, for example, whistling ducks which used to count 20000 counts today only 7000 .

5. The Flamingo is among the species which have decrease in number as revealed in the studies surveyed these species since the 90 s we used to have more than 2500 today we count only 250.

\subsection{Limitations}

To end this part of the results, some limitations are presented to unfold unanswered questions that our study did not address. One major constraint that faced this study is the lack of prior research studies on the topic in the Moroccan context. There is little, if any, prior research on this topic. This limitation can serve as an important opportunity for further research to examine eco-documentaries in Morocco from different perspectives. Due to the scope of the study, too focus on the linguistic component of the film, the visual component of the documentary was not dealt with even though scenes and images are complementary to the production's argumentative aim. Additionally, we mention that many narratives and stories of other characters (witnesses and the voice-over narrator) were not dealt with even their narratives and testimonies prevalence in the film has contributed a great deal to make the film's theme more understandable. 


\section{CONCLUSION}

The film conveys many truths about human malign interventionism in the Sidi Boughaba lagoon. The reality reported in experts' testimonies and scientific data reveals the despoliation of a lagoon in Northeast Morocco. To strengthen the argumentative flow, the eco-documentary calls upon scientific consultants to ascertain the perspective of the film and to reinforce environmental awareness among the audience. In this vein, two experts have been given roles and time to speak out their opinions about an immediate urgency, to protect and save the lagoon from man's intervention. The film offers different perspectives on the extent to which humans have critically damaged the lagoon. To examine the many discourses in the eco-documentary, experts' narratives were analyzed in terms of fear and threat indicators. The study discarded visuals though their combination to sound effects, music, and language brings about the argumentative objective of the film. From a critical discourse analysis and an ecolinguistics perspective, experts' narratives were analyzed to explain the extent to which they have used fear and threat expressions to report about the reality of the environmental setting. Their testimonies about the crisis are logic testimonies through which the film highlights threats, shows characters' preoccupations, and provides specific recommendations and solutions to improve the environmental issue. The presence of scientist figures made of this eco-documentary a relatively successful media production. We assume that most fear and threat appeals used in experts' narratives are related to the severity of the destructions perpetrated by man to the lagoon. Besides, many patterns have fearfully depicted the dramatic situation of the lagoon and species living or transiting by the place. Also, so many linguistic structures in experts' testimonies depict a language of fear that illustrates the deterioration of the lagoon regarding bird colonies, fish over-exploitation, and water salinity. Typically, experts' discourse is based on an elaborated language that expresses their scientific data about the environmental problem. The presence of scientific actors in the documentary is effective in that it logically communicates the impairment that the human being has provoked to the lagoon. This choice enabled the film to draw a clear narrative line to achieve the argumentative flow when reporting about the degradation of the natural setting. The analysis of experts' narratives shows that their discourse is rife with PSV and PSP patterns through which they point to the responsibility of human beings activities that are badly affecting the environmental setting. To illustrate their fears, the experts evoke the case of birds in which living cycles and patterns are intersected. Dramatically, the migration cycle of birds is threatened by illegal hunting that is severely damaging feeding areas and birthing grounds, report the two scientific experts.

\subsection{Recommendations}

In this critical suggestion regarding the best actions to remedy to a certain situation, we aim to provide some beneficial recommendations that will not certainly solve all the issues, but they might have beneficial outcomes to heighten the quality of eco-documentary productions in Moroccan on many levels.

\subsubsection{Governmental Organs and Non-governmental Organs}

In this section, we propose some suggestions that can be taken by governmental and non-governmental organizations in helping to secure, protect, and preserve the natural environment from destruction and abuse. In this context, we strongly believe that GO and NGO's must work towards the implementation of the following:

- The establishment of precautionary and repression measures.

- The lagoon, which is declared a RAMSA area, must be visually and physically isolated from humans to minimize extinction risks that threaten birds, plants, and fish. 
- The population must be informed through regional and national campaigns that the area is a natural reserve the management of which is restricted by regulations and human common interest.

\subsubsection{Eco-documentary Makers}

Knowing how to manage complex interactions between environmental issues and the characters' discourses in an eco-documentary is one of the major concerns of this analysis. Based on that, the following suggestions are provided:

- Professional training must be provided for new and emerging directors.

- Training programs must take into consideration linguistic and communicative dimensions.

- Argumentation strategies should rely on appealing narratives and testimonies to adequately portray threats and name perpetrators of offenses.

\subsubsection{Future Research}

Environment documentaries have profoundly changed the way people think about human-based natural crises. Despite its importance to inform and incite change, this media genre remains in many countries, including Morocco, poorly investigated by scientific research. Multidisciplinary approaches have to explore the environmental documentary from different perspectives including social, linguistic, cultural, and media levels. We believe that documentaries can help people perceive the reality in the discourses that report about the magnitude and severity of environmental crises caused by humans to many natural elements. In this sense, we suggest that more research is needed to:

- Examine complementarity and alignment of discourse and visuals in media productions that unveil ecological degradations, particularly when the misalignment causes ambiguity and vagueness of meaning in ecodocumentaries.

- Explore the use of linguistic features, precisely the prevalence or the absence of some linguistic features that mitigate hazardous realities of environmental disaster or obscures meaning-making of eco-documentaries.

- Investigate how and what for names of humans and industrials have been hidden by passive voice to disguise disastrous behaviors. In this vein, the use of agency and euphemism in eco-documentary narratives must be highlighted.

- Promote narratives, stories, and testimonies that celebrate the protection of the natural environment. From an ecolinguistic perspective, the discourse reporting about shocking environmental problems must by no means blur the signifier or avoid naming of the referent.

\section{REFERENCES}

Aitken, I. (2013). The concise Routledge encyclopedia of the documentary film. New York: Routledge.

Altman, R. (1999). Film/genre. London: BFI.

Armstrong, F. (Director). (2010). The age of stupid [Motion picture]. Toronto: Mongrel Media.

Arthus-Bertrand, Y. (Director). (2009). Home [moving picture]. Belgium: Europa Corp.

Aslani, M. (2014). Semiotics in the animated documentary. Journal of American Science, $10(1), 67-73$.

Aufderheide, P. (2007). Documentary film: A very short introduction. Oxford: Oxford University Press. 
Basa, I. (2009). Environmental discourse of architecture. International Journal of Environmental Studies, 66(2), 259-267.

Bawarshi, A. S., \& Reiff, M. (2010). Genre: An introduction to history theory research and pedagogy. West Lafayette: Parlor Press.

Bednarek, M. (2010). The language of fictional television drama and identity. New York: Continuum.

Bernard, S.C. (2007). Documentary storytelling making stronger and more dramatic nonfiction films. Oxford: Focal Press.

Biber, D. (2012). Register and discourse analysis. In J.P. Gee \& M. Handford (Eds.). The Routledge handbook of discourse analysis (pp: 191- 208). New York: Routledge.

Biber, D., Connor, U., \& Upton, T. A. (2007). Discourse on the move using corpus analysis to describe discourse structure. Amsterdam: John Benjamins.

Branigan, E. (1992). Narrative comprehension and Film. London: Routledge.

Buell, L. (2005). The future of environmental criticism. Oxford: Blackwell.

Buell, L., Heise, U.K., \& Thornber, K. (2011). Literature and environment. Annual Review of Environment and Resources, 36, 417- 440.

Cap, P. (2017). The language of fear communicating threat in public discourse. London: Palgrave Macmillan.

Chamalah, E., Nuryatin, A., Sayuti, S. A., \& Zulaeha, I. (2019). Functions of Character in Indonesian Folklore Princess of the Runaway Valley: A Study of Vladimir Propp Narrative Structure Theory. International Journal of Language and Literary Studies, 1(3), 60-70.

Chapman, J. L. (2009). Issues in contemporary documentary. Cambridge: Polity.

Conners, N., \& Conners, L. (Producers). (2007). The 11th Hour. [Moving picture]. United States: Warner Independent Pictures.

Dakki, M., CherKaoui, I., lahrouz, S., \& Saâd, H. (2013). Dix années de suivi des anatidés nicheurs sur le lac de Sidi Boughaba (Nord-West Marocain) situation tendances dévolution et perspective de recherche [Ten years of monitoring anatidae's nesting on the lake of Sidi Boughaba (North-West Morocco) situation evolution trends and research perspectives]. Revue D'écologie (Terre \& Vie), 68, 167-180.

Danesi, M. (2015). Advertising discourse. In K. Tracy, C. Ilie \& T. Sandel (Eds.). The international encyclopedia of language and social interaction (pp: 45-67). New Jersey: John Wiley.

Dixon, T. (1999). Inculcating wildness ecocomposition nature writing and the regreening of the American suburb. In M. Bennett \& D. W. Teague (Eds.). The nature of cities ecocriticism and urban environments (pp: 77 - 90). Tucson: University of Arizona.

Dobrin, S.I., \& Weisser, C. R. (2002). Natural discourse toward eco-composition. New York: New York University Press.

Dryzek, J. S. (2013). The politics of the earth environmental discourses. Oxford: Oxford University Press.

Elkington, J., Knight, P., \& Hailes, J. (1988). The green consumer guide from hairspray to hamburgers - shopping for a better environment. Melbourne: Penguin Books.

Ellis, J. (2000). Seeing things television in the age of uncertainty. London: I. B. Tauris.

Fairclough, N. (1995). Media discourse. London: Arnold.

Fairclough, N. (2003). Analyzing discourse textual analysis for social research. London: Routledge.

Faouzi, L. (Director). (2012). انين المرجة الزرقاء [whining of the blue lagoon]. [Moving picture]. Morocco: Faouzi Vision and SNRT. Downloaded from amoudou@faouzivision.ma 
Feldman, M. S., Skoldberg, I.K., Brown, R.N., \& Horner, D. (2004). Making sense of stories a rhetorical approach to narrative analysis. Journal of Public Administration Research and Theory, 14(2), 147 - 170.

Fill, A. (1993). Okolinguistik-Eine Einfuhrung. Tubingen: Narr.

Fill, A. (1998). Ecolinguistics state of the art. Arbeiten aus Anglestik Americanistik, 23(1-3), 3-16.

Fisher, S. (Producer). (2009). The Cove [Moving picture]. United States: Participant Media. Freedman, A., \& Medway, P. (1994). Locating genre studies antecedents and prospects. In A. Freedman \& P. Medway (Eds.). Genre and the new rhetoric (pp: 1-20). Bristol: Taylor and Francis.

Freedman, A., \& Artemeva, N. (2008). Introduction. In N. Artemeva \& A. Freedman (Eds.). Rhetorical genre studies and beyond (pp: 1-8). Winnipeg: Inkshed Publications.

Gerbig, A. (2000). Patterns of language use in discourse on the environment a corpus-based approach. In B. Ketteman \& H. Penz (Eds.). ECOnstructing language nature and society the ecolinguistic project revisited essays in honour of Alwin Fill (pp: 191-216). Tübingen: Stauffenburg.

Giddens, E. (2012). Encountering social-constructivist rhetoric teaching an environmental writing and literature course. In G. Garrard (Ed.). Teaching ecocriticism and green cultural studies (pp: 37- 48). London: Palgrave Macmillan.

Glotfelty, C., \& Fromm, H. (1996). The ecocriticism reader landmarks in literary ecology. Athens: University of Georgia Press.

Haeckel, E. (1866). Generelle morphologie der organismen. Berlin: G. Reimer.

Halliday, M. A. K. (2001). New ways of meaning challenge to applied linguistics. In A. Fill \& P. Muhlhausler (Eds.). The ecolinguistic reader Language ecology and environment (pp: 175-202). London: Continuum Press.

Harre, R., Brockmeier, J., \& Muhlhausler, P. (1999). Greenspeak a study of environmental discourse. London: Sage.

Haugen, E. (1971). The ecology of language. The linguistic reporter, 13(1), 19-26.

Haugen, E. (1972). The ecology of language. Stanford: Stanford University Press.

Haugen, E. (2001). The ecology of language, in A. Fill and P. Mühlhäusler (Eds.). The ecolinguistics reader language ecology and environment (pp: 57- 66). London: Continuum.

Hauser, G. A. (2002). Introduction to rhetorical theory. Illinois: Waveland Press Inc.

Health Communication Capacity Collaborative [HCCC]. (n d). The extended parallel processing model an $\mathrm{HC} 3$ research primer. Retrieved from https://healthcommcapacity.org

Herndl, C. G., \& Brown, S. C. (1996). Green culture environmental rhetoric in contemporary America. Madison: Univ. Wis. Press.

Hochman, J. (1997). Green cultural studies an introductory critique of an emerging discipline. Mosaic, 30(1), 81-97.

Hodosy, A. (2018). Biomovie eco-criticism and popular film. Szeged: Tiszataj Foundation.

Howard, P. (1978). Weasel words. London: Hamilton.

Hughes, H. (2014). Green documentary environmental documentary in the twenty-first century. Chicago: The University of Chicago Press.

Hulot, N., \& Lièvre, J.A. (Directors). (2009). Le Syndrome du Titanic. [Moving picture]. France: Studio 37, Mandarin Cinéma, Mars films, WLP, and TF1 Films.

Iedema, R. (2003). Multimodality resemiotization extending the analysis of discourse as multi-semiotic practice. Viual Communication, 2 (1), 29-57.

Ivakhiv, A. (2008). Green film criticism and its futures. Interdisciplinary Studies in Literature and Environment, 15(2), 1- 28. 
Kozloff, S. (1988). Invisible storytellers' voice-over narration in American fiction. Berkeley: University of California Press.

Kozloff, S. (2000). Overhearing film dialogue. Los Angeles: University of California Press.

Kress, G., \& van Leeuwen, T. (2006). Reading images the grammar of visual design. London: Routledge.

Laurie, L., Bender, L., \& Burns, S. Z. (Producers). (2006). The inconvenient truth [Moving picture]. United States: Paramount Classics.

Lovell, T. (1971). Sociology and the cinema. Screen, 12(1), 15 - 26.

Luke TW. (1997). Ecocritique contesting the politics of nature economy and culture. Minneapolis: Minneapolis University Press.

Martin, J. \& Rose, D. (2003). Working with discourse meaning beyond the clause. London: Continuum.

McIntyre, D., \& Culpeper, J. (2010). Activity types incongruity and humor. In D. McIntyre $\&$ B. Busse (Eds.). Language and style (pp: 204- 224). Basingstoke: Palgrave.

Milne, M. (Director). (2008). 2075 les temps changent. [Moving picture]. France, Canada: Wizzfilms inc.

Mliless, M., \& Larouz, M. (2018). An ecolinguistic analysis of environment texts in Moroccan English language teaching textbooks. International Journal of Research in Environment Studies, 5, 103-116.

Mliless, M., Larouz, M., \& Yacoulti, M. (2019). Language and visuals in contradiction a semiotic and discourse analysis of a Moroccan public service announcement for forest protection, The Malysian Journal of Media studies [JPMM], 21(2), 21-53.

Mliless, M. (2020). Environmental discourse analysis: Fear expressions in a Moroccan ecodocumentary. Beau Bassin: LAP Academic publishing.

Mühlhäusler, P. (1996). Linguistic adaptation to change environmental conditions some lessons from the past. In A. Fill, A. (Ed.). Sprach"okologie und Okolinguistik (pp: 105-130). Tubingen: Stauffenburg.

Mühlhäusler, P. (2000a). Humboldt Whorf and the roots of ecolinguistics. In M. Pütz \& M. Verspoor (Eds.). Explorations in linguistic relativity (pp: 89-99). Amsterdam: John Benjamins.

Mühlhäusler, P. (2000b). Language planning and language ecology. Current Issues in Language Planning, 1(3), 306 - 367.

Mühlhäusler, P. (2002). Ecology of languages. In R. B. Kaplan (Ed.). The Oxford handbook of applied linguistics (pp: 374-387). Oxford: Oxford University Press.

Mühlhäusler, P. (2003). Language of environment environment of language a course in ecolinguistics. London: Battlebridge.

Mühlhäusler, P., \& Fill, A. (2001). The ecolinguistics reader language ecology and environment. London: Continuum.

Mühlhäusler, P., \& Peace, A. (2006). Environmental discourses. Annual Review of Anthropology, 35(1), 457 - 479.

Nash, J. (2015). Placenames and ecolinguistics some considerations for toponymists. Arbeiten aus Anglistik und Amerikanistik, 40, (1/2), 68-71.

Nathansohn, R., \& Zuev, D. (2013). Introduction. In R. Nathansohn \& D.Zuev (Eds.). Sociology of the visual sphere (pp: 1-12). New York: Routledge.

Nichols, B. (1991). Representing reality. Bloomington: Indiana University Press.

Nichols, B. (2001). Introduction to documentary. Bloomington: Indiana University Press.

Pauwels, L. (2010). Visual sociology reframed an analytical synthesis and discussion of visual methods in social and cultural research. Sociological Methods and Research, 38(4), 545- 581. 
Paré, A., \& Smart, G. (1994). Observing genres in action towards a research methodology. In A. Freedman \& P. Medway (Eds.). Genre and the new rhetoric (pp: 146-154). Bristol: Taylor and Francis.

Piazza, R. (2006). The representation of conflict in the discourse of Italian melodrama. Journal of Pragmatics, 38, 2087-2104.

Piazza, R. (2010). Voice over and self-narrative in film a multimodal analysis of Antonioni's When Love Fails (Tentato Suicidio). Language and Literature, 19 (2), 173-195.

Piazza, R. (2011). Let's cinema speak discourse in French cinema and beyond. New York: Continuum.

Quaglio, P. (2008). Television natural dialogue and conversation linguistic and similarities functional differences. In A. Ädel \& R. Reppen (Eds.). Corpora and discourse the challenges of different settings (pp: 189-210). Amsterdam: John Benjamins.

Quaglio, P. (2009). Television dialogue the sitcom friends Vs. natural conversation. Amsterdam: John Benjamins.

Ramsar Convention Secretariat [RCS]. (2013). A guide to the convention on wetlands (Ramsar, Iran, 1971). Switzerland: Ramsar Convention Secretariat.

Renov, M. (1993). Theorizing documentary. New York: Routledge.

Rider, T.R. (2014). Environmental discourses and rhetoric in the conceptual space of architectural education. Enquiry, 11(1), 1-7.

Rose, G. (2001). Visual methodologies an introduction to the interpretation of visual Materials. London: Sage.

Rowe, S. J. (1989). What on earth is environment? Trumpeter, 6(4), 123-126.

Saidi, R. (2018). La production cinématographique sud-sud pour une dynamique africaine défis et perspectives du film documentaire au Maroc cas d'Amouddou [SouthSouth film production for an African dynamic challenges and perspectives of the documentary film in Morocco Case of Amouddou]. Langues Cultures Communication -L2C, 2(1), 115-126.

Schiffrin, D., Tannen, D., \& Hamilton, H. E. (2001). The handbook of discourse analysis. Oxford: Blackwell.

Short, M. (2007). How to make a drama out of a speech act the speech act of apology in the film 'A Fish Called Wanda'. In D. L. Hoover \& S. Lattig (Eds.). Stylistics prospect and retrospect (pp: 169-189). Amsterdam: John Benjamins.

Stokoe, E. (2008). Dispreferred shares and other interactional breaches have devices for occasioning audience laughter in television 'sitcoms'. Social Semiotics, 18 (3), 289-307.

Sufi, M. (2014). Ecocinema and the evolution of the documentary genre from the 11th Hour (2007) to the Age of Stupid (2009) and finally the Cove (2009). Retrieved from: https://www.researchgate.net/publication/276920527

Sztompka, P. (2008). The focus on everyday life a new turn in sociology. European Review, 16(1), 23-27.

Taylor, S. G. (1990). Naturalness the concept and its application to Australian ecosystems. The Proceedings of the Ecological Society of Australia, 16, 411-418.

Terry, M. (Director). (2010). The Antarctica challenge a global warning [Motion picture]. United States: Polar Cap Productions.

Trim J. (1959). Historical descriptive and dynamic linguistics. Language and Speech, 2(1), 9-25.

Van Dijk, T. A. (1991). News as discourse. New York: Erlbaum.

Walton, D. (2007). Argumentation dialectic persuasion and rhetoric. Cambridge: Cambridge University Press. 
Wildfeuer, J. (2014). Film discourse interpretation towards a new paradigm for multimodal film analysis. New York: Routledge.

Williams, R. (1983). Keywords a vocabulary of culture and society. New York: Oxford University Press.

Witte, K. (1992). Putting the fear back into fear appeals the extended parallel process model. Communication Monographs, 59, 329-349.

Witte, K., Cameron, K. A., McKeon, J., \& Berkowitz, J. (1996). Predicting risk behaviors development and validation of a diagnostic scale. Journal of Health Communication, 1, 317-341.

Wodak, W. (1988). Language power and ideology studies in political discourse. London: John Benjamins Publishing.

Wodak, W. (2015). The politics of fear what right-wing populist discourses mean. London: Sage Publications.

Zheni, T. (2020). Person Deixis as Biased Political Pronouns in George W. Bush's Speeches on Iraqi War II. International Journal of Language and Literary Studies, 2(1), 155-171.

Zuev, D., \& Krase, J. (2017). Visual sociology. Sociopedia.isa, 1-12. DOI: $10.1177 / 2056846017121$

\section{AUTHORS' BIO:}

Mohamed MLILESS graduated from Moulay Ismail University, Faulty of Arts. He received a PhD in Applied Linguistics. He published many books on legal and environmental discourse. The many scientific articles, he authored and coauthored, focused on social and environmental issues. Last but not least, Dr. MLILESS is a member of the International Ecolinguistics Association, a member of the "London Journals Press", and a member of "Acta Scientific Open International Library, India". Dr. Mohamed MLILESS is a review board member of the "Journal of Education Teaching and Social Studies" and the "Journal of Sustainability in Environment".

Lamiae AZZOUZI is an associate professor at Moulay Ismail University, faculty of Humanities department of English Meknes. Currently, Dr. AZZOUZI is a part-time teacher at ESISA school of Software Engineering and Applied Sciences, Fès; a member of the Master Program in Applied Linguistics since 2009; a member of the Applied Linguistics Doctorate Laboratory, and a member of the scientific committee of the English department. She published many articles in gender studies, media studies, and semiotics. 